OPEN ACCESS

Edited by:

Steven Joniau,

Universitaire Ziekenhuizen

Leuven, Belgium

Reviewed by:

Karel Decaestecker,

Ghent University, Belgium

Michael S. Floyd (Jr),

St. Helens and Knowsley Teaching Hospitals NHS Trust, United Kingdom

*Correspondence:

Clemens M. Rosenbaum rosenbaumclemens@gmail.com

Specialty section:

This article was submitted

to Genitourinary Surgery,

a section of the journal

Frontiers in Surgery

Received: 01 February 2017

Accepted: 24 July 2017

Published: 10 August 2017

Citation:

Kranz J, Reiss PC, Salomon G,

Steffens J, Fisch $M$ and

Rosenbaum CM (2017) Differences in

Recurrence Rate and De Novo

Incontinence after Endoscopic

Treatment of Vesicourethral Stenosis and Bladder Neck Stenosis.

Front. Surg. 4:44.

doi: 10.3389/fsurg.2017.00044

\section{Differences in Recurrence Rate and $D e$ Novo Incontinence after Endoscopic Treatment of Vesicourethral Stenosis and Bladder Neck Stenosis}

\author{
Jennifer Kranz', Philipp C. Reiss², Georg Salomon ${ }^{3}$, Joachim Steffens ${ }^{1}$, Margit Fisch $^{2}$ \\ and Clemens M. Rosenbaum ${ }^{2 *}$ \\ ${ }^{1}$ Department for Urology and Pediatric Urology, St. Antonius Hospital, Eschweiler, Germany, ${ }^{2}$ Department of Urology, \\ University Medical Center Hamburg-Eppendorf, Hamburg, Germany, ${ }^{3}$ Martini Klinik Prostate Cancer Center, University \\ Medical Center Hamburg-Eppendorf, Hamburg, Germany
}

Objectives: The objective of this study was to compare the recurrence rate and de novo incontinence after endoscopic treatment of vesicourethral stenosis (VUS) after radical prostatectomy (RP) and for bladder neck stenosis (BNS) after transurethral resection of the prostate (TURP).

Methods: Retrospective analysis of patients treated endoscopically for VUS after RP or for BNS after TURP at three German tertiary care centers between March 2009 and June 2016. Investigated endpoints were recurrence rate and de novo incontinence. Chi-squared tests and $t$-tests were used to model the differences between groups.

Results: A total of 147 patients underwent endoscopic therapy for VUS (59.2\%) or BNS (40.8\%). Mean age was 68.3 years (range 44-86), mean follow-up 27.1 months (1-98). Mean time to recurrence after initial therapy was 23.9 months (1-156), mean time to recurrence after prior endoscopic therapy for VUS or BNS was 12.0 months (1-159). Patients treated for VUS underwent significantly more often radiotherapy prior to endoscopic treatment (33.3 vs. 13.3\%; $p=0.006)$ and the recurrence rate was significantly higher (59.8 vs. 41.7\%; $p=0.031$ ). The overall success rate of TUR for VUS was $40.2 \%$, success rate of TUR for BNS was $58.3 \%$. TUR for BNS is significantly more successful $(p=0.031)$. The mean number of TUR for BNS vs. TUR for VUS in successful cases was 1.5 vs. 1.8, which was not significantly different. The rate of de novo incontinence was significantly higher in patients treated for VUS (13.8 vs. $1.7 \% ; p=0.011)$. After excluding those patients with radiotherapy prior to endoscopic treatment, the recurrence rate did not differ significantly between both groups (60.3\% for VUS vs. $44.2 \%$ for BNS; $p=0.091$ ), whereas the rate of de novo incontinence (13.8 for VUS vs. $0 \%$ for BNS; $p=0.005)$ stayed significantly higher in patients treated for VUS.

Abbreviations: VUS, vesicourethral stenosis; RP, radical prostatectomy; BNS, bladder neck stenosis; TURP, transurethral resection of the prostate. 
Conclusion: Most patients with BNS are successfully treated endoscopically. In patients with VUS, the success rate is lower. Both stenoses differ with respect to de novo incontinence. Patients must be counseled regarding the increased risk of de novo incontinence after endoscopic treatment of VUS, independent of prior radiotherapy. Longer follow-up is warranted to address long-term outcomes.

Keywords: benign prostate hyperplasia, bladder neck stenosis, prostate cancer, transurethral resection, vesicourethral stenosis

\section{INTRODUCTION}

Transurethral resection of the prostate (TURP) is still the most common and effective surgical method for the treatment of bladder outlet obstruction. Despite a significant reduction in the mortality rate, the morbidity of TURP is still about $15 \%$ and includes bleeding, urethral strictures, and the development of bladder neck stenosis (BNS) $(1,2)$. An extensive resection around the bladder neck may result in a stenosis, especially in small prostate glands (3). In the case of histologically proven prostatitis, the risk is even further increased (4). To prevent BNS, an additional incision of the internal sphincter could be an option for all smaller prostates. This incision causes a divergence of the internal fibers and thus an expansion of the bladder neck, but this is no guarantee for the prevention of a BNS (5). BNS occurs in about $0.3-9.2 \%$ of cases after TURP $(6,7)$, and no significant difference for BNS between bipolar vs. monopolar transurethral resection has been reported (8).

Besides radiotherapy, radical prostatectomy $(\mathrm{RP})$ is an integral component of prostate cancer treatment especially for organconfined tumors (9). A possible vulnerability after RP is the vesicourethral anastomosis, which is performed in single button technique or in a continuous manner. The incidence of vesicourethral stenosis (VUS) varies between 1.1 and 29\% (10-16), depending on cancer treatment type. Rates of VUS after RP differ depending on the surgical procedure; the development of VUS is more common after open radical retropubic in comparison to robot-assisted $\mathrm{RP}(12,17,18)$ and more common after open radical retropubic in comparison to radical perineal prostatectomy (13). After salvage RP for locally recurrent prostate cancer after radiation therapy, rates of VUS are higher than those observed after standard RP $(19,20)$.

Anastomotic insufficiencies can arise primarily postoperatively or develop by shifting of the catheter when the patient is mobilized. It has been shown that the frequency of incontinence and the development of VUS increase after anastomotic leakage (21-23).

Treatment of VUS after RP and BNS after TURP and their recurrences are always a therapeutic challenge, even for experienced urologists. Treatment is usually initiated with an endoscopic approach commonly involving dilatation, direct vision of the internal urethrotomy, a bladder neck incision according to Turner Warwick, or transurethral resection of the bladder neck (11). Often, treatment is complicated by a combination of stenosis and urinary incontinence. However, different studies have shown a declining success rate after repeated transurethral surgery (24).
Open surgical urethroplasty $(25,26)$ has been reported, as well as urinary diversion for recalcitrant stenoses (27).

In this study, we retrospectively analyzed patients treated endoscopically for VUS after RP or for BNS after TURP to compare recurrence rates and de novo incontinence. Our hypothesis is that the recurrence rates and rates of incontinence after therapy for either VUS or BNS are different.

\section{MATERIALS AND METHODS}

After obtaining Institutional Review Board approval, we retrospectively identified patients who underwent TUR for VUS or BNS from our institutional databases. We only included patients treated endoscopically for VUS after RP or for BNS after TURP. TUR was performed between March 2009 and June 2016. We excluded patients with laser treatment for VUS $(n=1)$ and patients with prior open simple prostatectomy $(n=2)$ due to small sample sizes.

Patients were interviewed by telephone using a standardized questionnaire (Supplementary Material) administered at the time of follow-up (FU). The questionnaire investigated previous urologic therapies (including radiation, endoscopic and open surgery), time to possible further therapy for the recurrence of VUS or BNS, type of further therapy and de novo incontinence after transurethral therapy.

Recurrence was determined as any need for further instrumentation such as catheterization, dilatation, internal urethrotomy, or open surgery. De novo incontinence was defined according to patient supplied information.

Descriptive statistics of categorical variables focused on frequencies and proportions. Means, ranges, and SDs are reported for continuously coded variables. Chi-squared tests and $t$-tests were used to model the differences between groups. All statistical analyses were performed using SPSS ${ }^{\circledR} 20.0$. The two-sided significance level was set at $p<0.05$.

\section{RESULTS}

We identified 147 patients who underwent endoscopic therapy for VUS or BNS. Sixty patients (40.8\%) underwent endoscopic treatment for BNS, and 87 patients (59.2\%) underwent endoscopic treatment for VUS. The mean age of the entire cohort was 68.3 (range 44-86) years, mean FU was 27.1 (1-98) months. The mean time to recurrence after initial therapy was 23.9 (1-156) months, and the mean time to recurrence after prior endoscopic therapy 
for VUS or BNS was 12.0 (1-159) months. The mean time between prior therapy (RP, TURP or endoscopic treatment of VUS, or BNS) and recent therapy was 16.6 (1-159) months. The median number of prior endoscopic therapies for VUS or BNS was 1 (IQR 0-1). Tables 1 and 2 show the baseline characteristics of patients treated for VUS and for BNS.

Table 3 demonstrates the differences between the two groups: patients treated for VUS underwent significantly more often radiation therapy prior endoscopic treatment (33.3 vs. $13.3 \%$; $p=0.006)$, and the recurrence rate was significantly higher (59.8 vs. $41.7 \% ; p=0.031$ ). Table 4 displays the success rate stratified by the number of procedures. The rate of de novo incontinence was significantly higher in patients treated for VUS ( 13.8 vs. $1.7 \% ; p=0.011$ ), too. Further on, we analyzed how many patients were successfully treated endoscopically. TUR for VUS was successful in $50 \%$ of all cases, TUR for BNS was successful in $70 \%$ of all cases. Therefore, endoscopic treatment for BNS was significantly more successful in patients suffering from BNS $(p=0.022)$. The mean number of endoscopic treatments in successful cases was 1.5 (1-4) in TUR for BNS, 1.8 (1-6) in TUR for VUS. The number of endoscopic maneuvers before success did not differ significantly.

When comparing success rate of those who underwent radiotherapy $(48.6 \%)$ vs. those who did not $(47.3 \%)$, we saw no statistically significant effect. These results were confirmed in further analysis, in which we excluded patients with radiation therapy prior to endoscopic treatment: the recurrence rate did not differ significantly between groups $(60.3 \%$ for VUS vs.

TABLE 1 | Patients treated for vesicourethral stenosis.

\begin{tabular}{lc}
\hline & $\boldsymbol{n}(\%)$ \\
\hline $\begin{array}{l}\text { Type of radical prostatectomy } \\
\text { Open } \\
\text { Laparoscopic/robot-assisted }\end{array}$ & $85(97.7)$ \\
Radiation therapy & $2(2.3)$ \\
No & \\
Low-dose BT & $57(65.5)$ \\
High-dose BT & $2(2.3)$ \\
Adjuvant EBRT & $1(1.1)$ \\
Prior transurethral resection of the prostate & $27(31.0)$ \\
Yes & \\
No & $6(6.9)$ \\
\hline
\end{tabular}

BT, brachytherapy; EBRT, external beam radiation therapy.

TABLE 2 | Patients treated for bladder neck stenosis.

\begin{tabular}{lc}
\hline & $\boldsymbol{n}(\%)$ \\
\hline Type of transurethral resection & \\
Transurethral resection of the prostate & $49(81.7)$ \\
Laser (HoLEP) & $6(10.0)$ \\
Incision & $5(8.3)$ \\
Radiation therapy & \\
No & $52(86.7)$ \\
Low-dose BT & $4(6.7)$ \\
High-dose BT & $2(3.3)$ \\
EBRT & $2(3.3)$ \\
\hline
\end{tabular}

$B T$, brachytherapy; EBRT, external beam radiation therapy.
$44.2 \%$ for BNS; $p=0.091$ ). Using cox regression analysis radiotherapy did not turn out to be a significant predictive factor for recurrence.

De novo incontinence ( 13.8 vs. $0 \% ; p=0.005$ ) stayed significantly higher in patients treated for VUS after excluding patients who had undergone radiation therapy.

\section{DISCUSSION}

This three-institutional analysis reports on the recurrence rate and the incidence of de novo incontinence after endoscopic treatment of VUS after RP and of BNS after TURP.

The retrospective data of 147 patients were analyzed (87 patients with VUS and 60 patients with BNS). VUS and BNS differed with respect to the recurrence rate and the de novo incontinence rate. We found higher recurrence rates and especially higher de novo incontinence rates in patients treated for VUS. The latter was independent from prior radiotherapy. Our hypothesis of different success and incontinence rates is thereby supported. This seems of utmost importance when counseling patients before therapy. Patients treated for VUS should be counseled about the burden of new onset incontinence especially after endoscopic therapy. There is a nonnegligible risk of de novo incontinence after endoscopic incision of VUS (13.8\%). As expected, only one patient with BNS suffered from de novo incontinence after multiple endoscopic

TABLE 3 | Comparison of patients treated for VUS and BNS

\begin{tabular}{|c|c|c|c|}
\hline & Vus & BNS & $p$-value \\
\hline Age [mean years (SD)] & $67.7( \pm 8.48)$ & $69.1( \pm 6.45)$ & n.s. \\
\hline $\begin{array}{l}\text { Time from initial therapy to } \\
\text { stenosis [mean month (SD)] }\end{array}$ & $28.14( \pm 31.28)$ & $19.36( \pm 20.54)$ & n.s. \\
\hline $\begin{array}{l}\text { Time from prior endoscopic therapy } \\
\text { to recurrence [mean month (SD)] }\end{array}$ & $12.31( \pm 24.36)$ & $11.31( \pm 16.63)$ & n.s. \\
\hline $\begin{array}{l}\text { Radiation therapy prior } \\
\text { endoscopic treatment, } n(\%)\end{array}$ & $29(33.3)$ & $8(13.3)$ & 0.006 \\
\hline Qmax, mean ml (SD) & $9.35( \pm 6.39)$ & $6.24( \pm 3.47)$ & n.s. \\
\hline PVR, mean ml (SD) & $78.54( \pm 87.25)$ & $126.63( \pm 31.4)$ & n.s. \\
\hline Recurrence, $n(\%)$ & $52(59.8)$ & $25(41.7)$ & 0.031 \\
\hline $\begin{array}{l}\text { Time to recurrence } \\
\text { [mean month }(\mathrm{SD})]\end{array}$ & $5.85( \pm 7.27)$ & $8.13( \pm 9.98)$ & n.s. \\
\hline De novo-incontinence, $n(\%)$ & $12(13.8)$ & $1(1.7)$ & 0.011 \\
\hline
\end{tabular}

BNS, bladder neck stenosis; VUS, vesicourethral anastomosis stenosis.

TABLE 4 | Success rates of patients treated by TUR for vesicourethral stenosis (VUS) and bladder neck stenosis (BNS), stratified by number of procedures.

\begin{tabular}{|c|c|c|c|c|c|}
\hline & \multicolumn{2}{|c|}{ TUR for VUS } & \multicolumn{2}{|c|}{ TUR for BNS } & \multirow[t]{2}{*}{$p$-value } \\
\hline & $\begin{array}{c}n \text { (successful } \\
\text { treated/all } \\
\text { treated pts) }\end{array}$ & $\%$ & $\begin{array}{c}n \text { (successful } \\
\text { treated/all } \\
\text { treated pts) }\end{array}$ & $\%$ & \\
\hline 1. TUR & $17 / 35$ & 48.6 & $22 / 34$ & 64.7 & n.s. \\
\hline 2. TUR & $12 / 26$ & 46.2 & $9 / 17$ & 52.9 & n.s. \\
\hline 3. TUR & $3 / 11$ & 27.3 & $3 / 5$ & 60.0 & n.s. \\
\hline$\geq 4$. TUR & $3 / 15$ & 20.0 & $1 / 4$ & 25.0 & n.s. \\
\hline
\end{tabular}


surgeries. Similarly, low rates of incontinence for BNS were described in the obtainable literature (24).

Regarding BNS after TURP in our study cohort, 58.3\% (35 of 60 ) were treated successfully, whereas $41.7 \%$ had a recurrence of the BNS. The mean time from initial therapy to stenosis was 19.36 months $( \pm 20.54)$; in the case of recurrence, the mean time from prior endoscopic therapy to recurrence was 11.31 months $( \pm 16.63)$. Comparing our data to the current literature, the results of endoscopic treatment for BNS are quite comparable. Pansadoro et al. presented data from 59 enrolled patients, with a mean age of 69 years and a median FU of 72 months (24). Of those patients, 51 (86\%) were treated successfully. A total of three patients underwent a successful second endoscopic procedure, for a final success rate of 91\% (54 of 59) (24). Recurrent strictures presented within 1 year after the operation at a median interval of 5 months (range 1-12) in their study (24), comparable with our own data.

Furthermore, Pansadoro et al. described some predisposing factors that have been suggested in the pathogenesis of type I strictures (BNS) after surgery on the prostate, including low average weight of the adenoma (12 g) compared with an overall median of $28 \mathrm{~g}$ and a subcervical adenoma with minimal residual urine (24). Due to missing data, e.g., weight of the adenoma, it is unfortunately not possible to state our own risk factors for the development of recurrences. These aspects will have to be considered in future research.

Consistent with the literature, patients suffering from VUS were treated successfully in $40.2 \%$ of cases (35 of 87$)(24,28)$. The mean time from initial therapy to stenosis was a bit longer than for BNS, but not significantly so.

The sole endoscopic treatment of recurrent BNS and VUS is generally associated with a high recurrence rate and is unsatisfactory for the patient as well as for the therapist due to frequent surgical interventions (29). Interesting combination treatments such as urethrotomy followed by HDR-brachytherapy (30) or internal urethrotomy followed by an adjuvant submucosal mitomycin injection (31) appear to have good short-term results, but experiences from larger series or long-term results are not available. Therefore, these treatment modalities cannot be recommended as a standard procedure.

Patients presenting with VUS and BNS should be informed about the outcomes of endoscopic therapy and the possibility of multiple procedures. As our results show, recurrent stenosis can be treated again endoscopically. However, the success rate after repeat endoscopic therapies decreases. Some studies have shown a declining success rate after repeated transurethral surgery $(24,28)$.

As our data show success rates of patients treated for VUS decrease with the number of endoscopic procedures (for third TUR only $27.3 \%$ ), whereas $60 \%$ of patients with BNS benefited from another endoscopic surgery. A quite low success rate is anticipated for more than four endoscopic treatments for both BNS and VUS and should only be offered in an exceptional case (e.g., in cases of poor general health or comorbidities).

From our point of view, a stepwise approach for therapy starts with an endoscopic incision or resection of the narrowed anastomosis or bladder neck. In cases of recalcitrant and intractable
VUS or BNS recurrences after repeated (for VUS, not more than three attempts) endoscopic therapies, we believe that patients require more invasive treatments. An open-operative, reconstructive procedure in a selected patient group with recurrent anastomotic strictures is preferable. Our preferred approach in cases of devastated bladder outlet obstruction is a transperineal reanastomosis for the treatment of highly recurrent VUS or a T-plasty or an YV-plasty for highly recurrent BNS $(32,33)$.

In most patients, in addition to obstructive micturition symptoms after frequent endoscopic interventions, de novo incontinence also develops; therefore, as a last resort treatment, a urinary diversion $(27,29,34)$ is an option as well. This surgical procedure can be carried out without significant complications, the medium-term results are very good and suggest a good quality of life for patients $(27,29)$.

There are several limitations to our study. First, it was retrospective study and a relatively small number of patients were included. Further, there is no standardized measurement to objectify the recurrence of a stricture or incontinence. Moreover, a longer FU is warranted to address long-term outcomes. Nevertheless, we are the first to determine differences in treatment outcomes for two different conditions, i.e., VUS and BNS. To the best of our knowledge, this is the first study to determine this difference.

In conclusion, VUS and BNS are different entities and should be handled as such. In our institutional experience, most patients with BNS are treated successful endoscopically. In patients with VUS, the success rate is lower. Both stenoses differ with respect to de novo incontinence. Patients must be counseled about the increased risk of de novo incontinence after endoscopic treatment of VUS, independent of prior radiotherapy.

\section{ETHICS STATEMENT}

We declare that, prior to the start of the study, all participating centers had attained ethical committee approval by their institutional review boards. Initial ethical committee approval was received in Hamburg (PV5205). The study was conducted in accordance with the Declaration of Helsinki (amendment by the 64th WMA General Assembly, Fortaleza, Brazil, October 2013).

\section{AUTHOR CONTRIBUTIONS}

JK: acquisition of data for the work, drafting the work, final approval of the version to be published, agreement to be accountable for all aspects of the work in ensuring that questions related to the accuracy or integrity of any part of the work are appropriately investigated and resolved. CR: substantial contributions to the conception of the work, revising the work critically for important intellectual content, final approval of the version to be published, agreement to be accountable for all aspects of the work in ensuring that questions related to the accuracy or integrity of any part of the work are appropriately investigated and resolved. GS, MF: substantial contributions to the design of the work, revising the work critically for important intellectual content, final approval of the version to be published, agreement to be accountable for all aspects of the work in ensuring that 
questions related to the accuracy or integrity of any part of the work are appropriately investigated and resolved. JS: analysis and interpretation of data for the work, revising the work critically for important intellectual content, final approval of the version to be published, agreement to be accountable for all aspects of the work in ensuring that questions related to the accuracy or integrity of any part of the work are appropriately investigated and resolved. CR: substantial contributions to the conception and design of the work; acquisition, analysis and interpretation of data for the work; drafting the work and revising it critically for important intellectual content; final approval of the version to be published; agreement to be accountable for all aspects of the work in ensuring that questions related to the accuracy or

\section{REFERENCES}

1. Strope SA, Yang L, Nepple KG, Andriole GL, Owens PL. Population based comparative effectiveness of transurethral resection of the prostate and laser therapy for benign prostatic hyperplasia. J Urol (2012) 187:1341-5. doi:10.1016/j.juro.2011.11.102

2. Reich O, Gratzke C, Bachmann A, Seitz M, Schlenker B, Hermanek P, et al. Morbidity, mortality and early outcome of transurethral resection of the prostate: a prospective multicenter evaluation of 10,654 patients. J Urol (2008) 180:246-9. doi:10.1016/j.juro.2008.03.058

3. Lee YH, Chiu AW, Huang JK. Comprehensive study of bladder neck contracture after transurethral resection of prostate. Urology (2005) 65:498. doi:10.1016/j.urology.2004.10.082

4. Doluoglu OG, Gokkaya CS, Aktas BK, Oztekin CV, Bulut S, Memis A, et al. Impact of asymptomatic prostatitis on reoperations due to urethral stricture or bladder neck contracture developed after TUR-P. Int Urol Nephrol (2012) 44:1085-90. doi:10.1007/s11255-012-0127-y

5. Leyh H, Necknig U. Transurethrale Resektion der Prostata: Komplikationsmanagement. Urologe (2014) 53:699-705. doi:10.1007/s00120-0143483-7

6. Rassweiler J, Teber D, Kuntz R, Hofmann R. Complications of transurethral resection of the prostate (TURP) - incidence, management, and prevention. Eur Urol (2006) 50(5):969-79. doi:10.1016/j.eururo.2005.12.042

7. Gravas S, Bach T, Drake M, Gacci M, Gratzke C, Herrmann TRW, et al. Treatment of non-neurogenic male LUTS. Edn. Presented at the EAU Annual Congress London 2017. Arnhem, The Netherlands: EAU Guidelines Office (2017).

8. Tang Y, Li J, Pu C, Bai Y, Yuan H, Wei Q, et al. Bipolar transurethral resection versus monopolar transurethral resection for benign prostatic hypertrophy: a systematic review and meta-analysis. J Endourol (2014) 28(9):1107-14. doi:10.1089/end.2014.0188

9. Mottet N, Bellmunt J, Bolla M, Briers E, Cumberbatch MG, De Santis M, et al. EAU-ESTRO-SIOG guidelines on prostate cancer. Part 1: screening, diagnosis, and local treatment with curative intent. Eur Urol (2017) 71(4): 618-29. doi:10.1016/j.eururo.2016.08.003

10. Elliott SP, Meng CV, Elkin EP, Mcaninch JW, Duchane J, Carroll PR, et al. Investigators incidence of urethral stricture after primary treatment for prostate cancer. Data from CaPSURE. J Urol (2007) 178(2):529-34. doi:10.1016/j. juro.2007.03.126

11. Herschorn S, Elliott S, Coburn M, Wessells H, Zinman L. SIU/ICUD consultation on urethral strictures: posterior urethral stenosis after treatment of prostate cancer. Urology (2014) 83:59-70. doi:10.1016/j.urology.2013. 08.036

12. Carlsson S, Nilsson AE, Schumacher MC, Jonsson MN, Volz DS, Steineck G, et al. Surgery-related complications in 1253 robot-assisted and 485 open retropubic radical prostatectomies at the Karolinska University Hospital, Sweden. Urology (2010) 75(5):1092-7. doi:10.1016/j.urology.2009. 09.075

13. Gillitzer R, Thomas C, Wiesner C, Jones J, Schmidt F, Hampel C, et al. Single center comparison of anastomotic strictures after radical perineal and radical retropubic prostatectomy. Urology (2010) 76(2):417-22. doi:10.1016/j. urology.2009.10.009 integrity of any part of the work are appropriately investigated and resolved.

\section{ACKNOWLEDGMENTS}

This work is a collaborative project of the GeSRU Academics group "Reconstructive Urology."

\section{SUPPLEMENTARY MATERIAL}

The Supplementary Material for this article can be found online at http://journal.frontiersin.org/article/10.3389/fsurg.2017.00044/ full\#supplementary-material.

14. Borboroglu PG, Sands JP, Roberts JL, Amling CL. Risk factors for vesicourethral anastomotic stricture after radical prostatectomy. Urology (2000) 56(1):96-100. doi:10.1016/S0090-4295(00)00556-2

15. Hu JC, Gold KF, Pashos CL, Mehta SS, Litwin MS. Role of surgeon volume in radical prostatectomy outcomes. J Clin Oncol (2003) 21(3):401-5. doi:10.1200/ JCO.2003.05.169

16. Erickson BA, Meeks JJ, Roehl KA, Gonzalez CM, Catalona WJ. Bladder neck contracture after retropubic radical prostatectomy: incidence and risk factors from a large single-surgeon experience. BJU Int (2009) 104(11):1615-9. doi:10.1111/j.1464-410X.2009.08700.x

17. Krambeck AE, DiMarco DS, Rangel LJ, Bergstralh EJ, Myers RP, Blute ML, et al. Radical prostatectomy for prostatic adenocarcinoma: a matched comparison of open retropubic and robot-assisted techniques. BJU Int (2009) 103(4):448-53. doi:10.1111/j.1464-410X.2008.08012.X

18. Wang R, Wood DP Jr, Hollenbeck BK, Li AY, He C, Montie JE, et al. Risk factors and quality of life for post-prostatectomy vesicourethral anastomotic stenoses. Urology (2012) 79(2):449-57. doi:10.1016/j.urology. 2011.07.1383

19. Stephenson AJ, Scardino PT, Bianco FJ Jr, DiBlasio CJ, Fearn PA, Easrham JA. Morbidity and functional outcomes of salvage radical prostatectomy for locally recurrent prostate cancer after radiation therapy. J Urol (2004) 172:2239-43. doi:10.1097/01.ju.0000140960.63108.39

20. Heidenreich A, Ohlmann C, Özgür E, Engelmann UH. Salvage radical prostatectomy in locally recurrent prostate cancer following radiation therapy. Urologe A (2006) 45:474-81. doi:10.1007/s00120-006-0995-9

21. Tyritzis SI, Katafigiotis I, Constantinides CA. All you need to know about urethrovesical anastomotic urinary leakage following radical prostatectomy. J Urol (2012) 188:369-76. doi:10.1016/j.juro.2012.03.126

22. Surya BV, Provet J, Johanson KE, Brown J. Anastomotic strictures following radical prostatectomy: risk factors and management. J Urol (1990) 143:755-8. doi:10.1016/S0022-5347(17)40082-6

23. Kostakopoulos A, Argiropoulos V, Protogerou V, Tekerlekis P, Melekos M. Vesicourethral anastomotic strictures after radical retropubic prostatectomy: the experience of a single institution. Urol Int (2004) 72:17-20. doi:10.1159/000075267

24. Pansadoro V, Emiliozzi P. Iatrogenic prostatic urethral strictures: classification and endoscopic treatment. Urology (1999) 53:784. doi:10.1016/ S0090-4295(98)00620-7

25. Young BW, Goebel JL. Retropubic wedge excision in congenital vesical neck obstruction. Stanford Med Bull (1954) 12:106.

26. Young BW. The retropubic approach to vesical neck obstruction in children. Surg Gynecol Obstet (1953) 96:150.

27. Kranz J, Anheuser P, Rausch S, Fechner G, Braun M, Müller SC, et al. Continent ileovesicostomy after bladder neck closure as salvage procedure for intractable incontinence. Cent European J Urol (2014) 66:481-6. doi:10.5173/ceju.2013.04.art25

28. LaBossiere JR, Cheung D, Rourke K. Endoscopic treatment of vesicourethral stenosis after radical prostatectomy: outcomes and predictors of success. J Urol (2016) 195(5):1495-500. doi:10.1016/j.juro.2015.12.073

29. Pfister D, Epplen R, Porres-Knoblauch D, Heidenreich A. Operative Korrekturmöglichkeiten der Anastomosenstriktur nach radikaler Prostatektomie. Urologe (2011) 50:1392-5. doi:10.1007/s00120-011-2716-2 
30. Kröpfl T, Olschewski MH. Seegenschmiedt Endoluminale Brachytherapie zur Vorbeugung von rezidivierenden Strikturen nach Urethrotomia interna. Urologe (2004) 43:1254-61. doi:10.1007/s00120-004-0630-6

31. Mazdak H, Meshki I, Ghassami F. Effect of mitomycin C on anterior urethral stricture recurrence after internal urethrotomy. Eur Urol (2007) 51:1089-92. doi:10.1016/j.eururo.2006.11.038

32. Reiss CP, Rosenbaum CM, Becker A, Schriefer P, Ludwig TA, Engel O, et al. The T-plasty: a modified YV-plasty for highly recurrent bladder neck contracture after transurethral surgery for benign hyperplasia of the prostate: clinical outcome and patient satisfaction. World J Urol (2016) 34(10):1437-42. doi:10.1007/s00345-016-1779-5

33. Reiss CP, Pfalzgraf D, Kluth LA, Soave A, Fisch M, Dahlem R. Transperineal reanastomosis for the treatment for highly recurrent anastomotic strictures as a last option before urinary diversion. World J Urol (2014) 32(5):1185-90. doi:10.1007/s00345-013-1180-6
34. Riedmiller H, Kocot A. The devastated bladder outlet: treatment options. Curr Opin Urol (2015) 25(4):352-6. doi:10.1097/MOU.0000000000000185

Conflict of Interest Statement: This study was conducted in the absence of any commercial or financial relationships that could be construed as a potential conflict of interest.

Copyright (C) 2017 Kranz, Reiss, Salomon, Steffens, Fisch and Rosenbaum. This is an open-access article distributed under the terms of the Creative Commons Attribution License (CC BY). The use, distribution or reproduction in other forums is permitted, provided the original author(s) or licensor are credited and that the original publication in this journal is cited, in accordance with accepted academic practice. No use, distribution or reproduction is permitted which does not comply with these terms. 